\title{
LA ABOGACÍA DE MELILLA Y LA UNED
}

\author{
Blas Jesús Imbroda Ortiz \\ Decano del Ilustre Colegio de Abogados de Melilla \\ Doctor en Derecho \\ Profesor Tutor de Derecho Penal II del Centro UNED Melilla
}

Resumen: El artículo realiza un recorrido histórico por muchos aspectos que vinculan el desarrollo de la abogacía en Melilla con la formación en la carrera de Derecho impartida en el Centro Universitario UNED Melilla. Tras valorar históricamente la constitución del Colegio de Abogados de Melilla, y sus primeros pasos, el autor vincula la importancia que el Centro UNED ha tenido en el mundo de la abogacía melillense, en su constitución y el importante peso en cuanto a las titulaciones obtenidas en esta universidad en los componentes actuales del citado Colegio. También se abordan importantes hitos en el desarrollo cultural y formativo, jornadas, conferencias y donde también se produce esta estrecha colaboración entre instituciones.

Palabras clave: Colegio de Abogados, UNED Melilla, Derecho, carreras universitarias, formación cultural.

Abstract: This article realises a historical tour throughout many aspects that link the legal profession development in Melilla with the academic training in law degree at the university center "UNED Melilla". After valuing historically, the formation of the Bar Association in Melilla, and its first steps, the author links the importance that the centre UNED has had in the world of legal profession amongst Melilla's inhabitants, in its creation and in the importance weight according to the degrees obtained in the current components of the mentioned Bar in this university. Furthermore, important milestones are dealing with the cultural and educational development, conferences, speeches where it is produced a narrow cooperation between institutions.

Key words: Bar Association, UNED Melilla, law, university degrees, cultural training.

Desde los inicios del siglo XX en Melilla la abogacía demandará y reivindicará la legítima defensa de los derechos de los ciudadanos. El ejercicio profesional no fue posible en la ciudad hasta el año 1914.Y no fue hasta el año 
1917 cuando se autoriza la jurisdicción ordinaria en la ciudad, dejando de tener la competencia exclusiva en todos los ámbitos la jurisdicción castrense.

La abogacía de la ciudad se organizará primero en el año 1914 en una asociación, hasta definitivamente crear en el año 1932 el Colegio de Abogados.

Para el mundo jurídico de la ciudad y para la propia abogacía, constituirá un punto histórico de inflexión la creación en el año 1976 de la UNED en Melilla. La carrera de Derecho impartida desde la creación de la UNED con una importante afluencia de alumnos desde sus inicios, propiciará que el Colegio se vea paulatina y progresivamente incrementado con los Licenciados que salían de sus aulas. Ello además de que la UNED, foco cultural e intelectual de la ciudad durante el último cuarto del siglo pasado, propiciará la celebración de numerosas actividades formativas en el ámbito jurídico, la mayoría en colaboración con el Colegio de Abogados, llegando a consolidar anualmente una de las Jornadas Jurídicas de más relevancia en el ámbito nacional, las Jornadas “Enrique Ruiz Vadillo”. La especial atención que desde su inicio tuvo la UNED con Derecho lo constituye el hecho de que la conferencia inaugural la impartiera el Catedrático de Derecho Penal José Antonio Sainz Cantero de la Universidad de Granada, y melillense de nacimiento. Versó sobre "La mujer ante el Código Penal. Necesidad de una reforma” y la pronunció el 3 de marzo de 1976.

\section{La fundación del Colegio de Abogados}

Melilla vivió históricamente una situación de excepcionalidad en su régimen jurídico derivado del concepto de que se trataba de una ciudad en guerra o en riesgo de guerra. Consecuencia de esta excepcionalidad fue que todas las contiendas jurídicas estaban sometidas con carácter exclusivo a la jurisdicción militar. No solo el ámbito penal sino también el civil, habían estado sometidos a la jurisdicción castrense, ante la que no podían ejercer los abogados que ya residían en la ciudad.

La creación del Juzgado de Primera Instancia, en virtud de la modificación del Código de Justicia Militar, que era una demanda de la opinión pública local y nacional, constituyó un paso determinante en la normalización de la ciudad, desproveyéndola de su condición exclusivamente militar. Por Real 
Decreto de de 3 de marzo de $1917^{1}$, se dispuso que para conocer de los negocios judiciales, tanto civiles como criminales que se promuevan en las ciudades de Ceuta y Melilla y sus términos municipales, se creará un Juzgado de primera instancia y de instrucción en cada una de las mencionadas Plazas, con iguales facultades y con la misma competencia que los demás de la jurisdicción ordinaria de la Península é islas adyacentes.

En junio de 1914 por el Ministerio de Guerra se autorizó a los Abogados y Procuradores de los Tribunales para el libre ejercicio de sus profesiones en Melilla ${ }^{2}$, siempre que cumpliesen, como señalaba la Real Orden, los requisitos que las Leyes y Reglamentos que exigían para ello y considerándose a estos efectos como Juzgado de término el de dicha plaza.

Esta autorización fue el resultado de una reivindicación que hacían los abogados que ya estaban establecidos en la ciudad, y a los que, sin embargo, de forma anormal se les impedía la defensa ante los tribunales.

Para ello, celebraron reuniones los abogados y procuradores en diciembre del año anterior, en el Círculo Mercantil. Habían tenido un primer encuentro convocado por los abogados Roberto Cano, José María Paniagua y Francisco del Canto y el procurador Antonio Jiménez. A partir de la reunión se crearía una comisión compuesta por el letrado Francisco del Canto y el procurador Antonio Jiménez para que redactaran un reglamento con el fin de colegiarse ${ }^{3}$.

En abril, la recién creada Asociación de Abogados y Procuradores de Melilla ya tenía reglamento y era enviado a los Colegios de Abogados y Juzgados de Instrucción de toda España junto a la resolución de su constitución. En dicha reunión (celebrada el 27 de abril de 1914) se acordó contestar en sentido negativo a la solicitud pidiendo la concesión de derechos civiles a Melilla por no entrar entre los fines de dicha asociación ${ }^{4}$.

\footnotetext{
${ }^{1}$ España. Real Decreto de 3 de ma rzo de 1917. Gaceta de Madrid, 4 de marzo de 1917, nº6, p. 540 .

${ }^{2}$ España. Real Decreto 1914 de 8 de junio, autorizando a los Abogados y Procuradores para el libre ejercicio de sus profesiones en Melilla, previo el cumplimiento de los requisitos que las Leyes y Reglamentos exigen para ello y considerándose a estos efectos como Juzgado de término el de dicha Pieza. Gaceta de Madrid, 10 de junio de 1914, nº 161, p. 676.

3 “Abogados y procuradores”. El Telegrama del Rif, 13 de diciembre de 1913.

4 “Abogados y procuradores”. El Telegrama del Rif, 28 de abril de 1914.
} 
El día 3 de enero de 1915 la Sociedad de Abogados y Procuradores se reunió nuevamente en el Círculo Mercantil, su domicilio provisional, tomando posesión la nueva Junta Directiva que estaba compuesta por José María Paniagua como Presidente, Ramón Pérez Agacino, y Trinidad Ortiz como Tesorera.

Durante el periodo de la $2^{a}$ República, los días dieciséis y diecisiete de junio de mil novecientos treinta y dos, los Abogados de Melilla se reunieron para aprobar los primeros Estatutos y acordar remitirlos al Ministro de Justicia, (por aquel entonces V. Cantos, del Partido Republicano Radical), por conducto de la Audiencia Provincial de Málaga, solicitando la aprobación de la constitución del Colegio de Abogados en la ciudad. Se creó una Comisión Gestora integrada por los Abogados Leopoldo Queipo Camó, Francisco García Vandewalle y Ramiro Ramos Acosta.

Previos los trámites previstos en la Real Orden de 23 de mayo de 1928, el Ministro de Justicia aprobó los Estatutos y concedió la colegiación a los Abogados de Melilla, en virtud de Orden de fecha 15 de septiembre de 1932, dando traslado de la misma a todos los Letrados por conducto del Juzgado de Primera Instancia de Melilla.

A las dieciocho horas y treinta minutos del día 24 de septiembre de 1932, en el salón de actos de la Cámara de la Propiedad Urbana, sito en la calle Pablo Iglesias n 23 (actual calle O’Donnell), se celebraba la Junta General por la que se constituía el Colegio de Abogados de Melilla ${ }^{5}$.

Asistieron los Abogados en ejercicio Leopoldo Queipo Camó, Francisco García Vandewalle, Vicente DíazAroniz, José María Paniagua Santos, Juan Castelló Requena, José López y López, José León Luna, José Sánchez del Rosal, Francisco del CantoVázquez, José Asensi Marín y Emilio de Viguera Franco.

Ejercían la profesión en aquellas fechas, además de los mencionados Juan Sánchez Fernández, Carmelo Abellán y García Polo, Carlos Echeguren Ocio, Federico Pita Espelosín, Federico J. Pita Molina y José Rotger.

\footnotetext{
${ }^{5}$ Colegio de Abogados de Melilla. Libro 1 “Actas de Junta de General”. Acta 24 de septiembre de 1932 .
} 
Impulsó y tuvo una actuación intensa en la creación del Colegio, el Abogado no ejerciente Luis Yrisarry Pastor.

Fue elegido primer Decano del Colegio José María Paniagua Santos, integrando la Junta de Gobierno los siguientes: Diputado $1^{\circ}$ Vicente Díaz Aroniz; Diputado $2^{\circ}$ Leopoldo Queipo Camó; Diputado $3^{\circ}$ José Asensi Marín; Diputado $4^{\circ}$ Emilio de Viguera Franco; Tesorero Juan Castelló Requena; y Secretario Francisco García Vandewalle.

En la primera Junta General se aprobó el presupuesto para afrontar los primeros gastos del Colegio, estableciéndose en la primera reunión de la Junta de Gobierno una cuota mensual de cinco pesetas, y una cuota de ingreso al Colegio de ciento cincuenta pesetas.

Constituyó una de las primeras preocupaciones de aquel incipiente Colegio, evitar la actuación de colegiados procedentes de la península, sin darse de alta en el Colegio. Se llegó a suscitar una discrepancia de criterios entre el presidente de la Audiencia Provincial de Málaga y el Colegio, por admitir aquel la actuación de Abogados no colegiados en juicios ante la Sección especial que semestralmente se desplazaba desde Málaga. Hubo que formular una reclamación ante el Ministro de Justicia, quien amparó la postura del Colegio de Abogados de Melilla.

Se crearon tres turnos de oficio, uno de asuntos y procedimientos de índole civil, otro de causas criminales con penas de prisión o presidio mayor o pena de mayor gravedad, y otro de causas criminales con las restantes penas.

Igualmente se solicitó que se habilitara una sede para el Colegio, en las dependencias del Juzgado de Primera Instancia e Instrucción, que se encontraba en la primera planta, izquierda, del actual edificio de calle O’Donnell $\mathrm{n}^{\circ} 4$. Le fue concedida una habitación, que amueblada constituyó la primera sede del Colegio.

El día 19 de noviembre de 1932 celebraron los Abogados junto al Juez de $1^{a}$ Instancia y Secretario del Juzgado, una comida en el restaurante de la Hípica para solemnizar la constitución del Colegio.

El 28 de enero de 1934 presenta la dimisión el Decano José María Paniagua por haber sido destinado al Registro de la Propiedad de La Caroli- 
na. No le fue admitida la dimisión, mientras tuviera residencia en Melilla y siguiera como Abogado ejerciente del Colegio. Una vez se ausentó definitivamente de la ciudad, cesó como Decano, siendo elegido en la Junta General celebrada el 6 de mayo de 1934, Vicente Díaz Aroniz, segundo Decano en la historia del Colegio.

Otra de las grandes ocupaciones del Colegio en sus inicios, fueron los continuos intentos porque se creara en Melilla una Sección permanente de la Audiencia Provincial de Málaga. En la misma Junta General de 29 de enero se acordó delegar en los Abogados José León Luna y Cándido López Castillejo para que en unión del Diputado a Cortes por Melilla y Abogado Carlos Echeguren, marcharan a Madrid y realizaran gestiones para la creación de la Sección permanente de la Audiencia en Melilla.

También en mayo de 1934, los Abogados acordaron buscar un local propio en el centro de la población, para instalar la sede del Colegio. Sin embargo, no era posible conseguirla "por la carestía de las viviendas y la escasez de medios económicos con que el Colegio cuenta" ${ }^{6}$.

En 1936 era Secretario de la Junta de Gobierno Cándido López Castillejos, destacado Abogado y activo miembro de la vida cultural de la ciudad. Firmó su última acta el día 26 de junio de 1936. Poco más de un mes después, concretamente el día 14 de agosto de 1936 fue asesinado, consecuencia de la represión consiguiente a la sublevación militar de julio de 1936. En este mismo periodo fue fusilado el Abogado José Rotger, Capitán de Estado Mayor que no se unió a la sublevación.

La situación durante la guerra civil provocó la suspensión del funcionamiento del Colegio. En reunión mantenida en el Juzgado de Primera Instancia el día 3 de mayo de 1938 bajo la presidencia de Juan Castelló Requena único miembro de la Junta de Gobierno anterior a la guerra civil, en el local sito en el Juzgado de Primera Instancia, celebraron Junta General extraordinaria, a la que asistieron los Letrados Carmelo Abellán García y Polo, Fernando Gamarra Lega y Francisco del CantoVázquez, únicos componentes en esos momentos del Colegio. Acorda-

${ }^{6}$ Colegio de Abogados de Melilla. Libro 10 “Actas de Junta de Gobierno”. Acta 27 de enero de 1935. 
ron "ante la anormalidad de las circunstancias actuales y poco número de colegiados, no es posible que se funcione con el prestigio que requiere la misión del Colegio, y estima que hasta llegar a la normalidad o hasta cuando el momento lo aconseje, se suspenda el funcionamiento en todos sus aspectos, participándolo al Sr. Juez de $1^{a}$ Instancia, a fin de que los derechos y deberes que le competen a nuestra organización, pasen a la referida autoridad, haciéndole entrega provisionalmente de la documentación y bienes del Colegio"7.

El día 4 de junio de 1941, reanudó su funcionamiento el Colegio, nombrándose Decano a José Sánchez del Rosal ${ }^{8}$.

\section{Abogados formados en la UNED-Melilla}

Muchos de los Licenciados en Derecho por la UNED, a medida que iban finalizando las carreras, fueron incorporándose al Colegio de Abogados de Melilla llegando a constituir uno de los grupos más numerosos en la abogacía melillense.

El primer licenciado procedente de la UNED que se colegia fue Manuel de la Cámara Diaz, incorporándose el día 27 de enero de 1984 como abogado no ejerciente. Nacido en el año 1923 y tras estudiar el bachillerato en el Colegio La Salle el Carmen de Melilla, ingresó en la Escuela Naval Militar en 1942. Desarrolló su carrera militar en distintos destinos y estuvo embarcado en buques de la entonces denominada Escuadra (crucero "Galicia", crucero "Miguel de Cervantes", minador "Vulcano" y en la plana mayor de la flotilla de destructores de Ferrol). Con el empleo de Teniente de Navío fue destinado a la Comandancia Militar de Marina de Melilla donde desempeñó varios cargos, entre los que cabe destacar el nombramiento de Interventor de Marina de la jurisdicción de Nador durante el proceso de independencia de Marruecos. A mediados de la década de los años sesenta se le diagnosticó "retinitis pigmentaria" que le hizo perder paulatinamente la visión en ambos ojos. En 1975 se matriculó en la carrera de Derecho del centro de la UNED

\footnotetext{
${ }^{7}$ Colegio de Abogados de Melilla. Libro 1 “Actas de Junta de Gobierno”. Acta 3 de mayo de 1938.

${ }^{8}$ Colegio de Abogados de Melilla. Libro $1^{\circ}$ “Actas de Junta de Gobierno”. Acta 4 de junio de 1941.
} 
de Melilla. Para cursar esta carrera contó con el apoyo de su esposa $\mathrm{M}^{\mathrm{a}}$ del Carmen Jiménez López y de sus hijos que le grababan los temas para así poder estudiar a diario las asignaturas. Con esta dificultad, pero con una extraordinaria y admirable voluntad, se licenció en Derecho por la UNED. Falleció el día 3 de enero de 2006.

El primer abogado ejerciente que se incorpora al Colegio de Melilla procedente de la UNED fue Fernando Meliveo Benchimol ${ }^{9}$ el día 10 de diciembre de 1985.

Los abogados que se incorporaron al Colegio procedentes de la UNED tanto como abogados ejercientes como no ejercientes fueron:

\begin{tabular}{|l|l|}
\hline 1984 & 1 \\
\hline 1985 & 3 \\
\hline 1986 & 2 \\
\hline 1988 & 1 \\
\hline 1989 & 4 \\
\hline 1990 & 2 \\
\hline 1992 & 3 \\
\hline 1993 & 8 \\
\hline 1994 & 6 \\
\hline 1995 & 6 \\
\hline 1996 & 5 \\
\hline 1997 & 2 \\
\hline 1998 & 1 \\
\hline 1999 & 4 \\
\hline 2000 & 1 \\
\hline 2001 & 8 \\
\hline 2002 & 3 \\
\hline 2003 & 5 \\
\hline & \\
\hline
\end{tabular}

${ }^{9}$ Continúa en el ejercicio profesional de la abogacía desde dicha fecha además de ser profesor tutor de la UNED donde imparte la asignatura de derecho del Trabajo y Derecho de los Servicios Públicos Sociales. 


\begin{tabular}{|l|l|}
\hline 2004 & 3 \\
\hline 2005 & 2 \\
\hline 2006 & 9 \\
\hline 2007 & 5 \\
\hline 2008 & 4 \\
\hline 2009 & 2 \\
\hline 2010 & 2 \\
\hline 2011 & 8 \\
\hline 2012 & 8 \\
\hline 2013 & 10 \\
\hline 2014 & 1 \\
\hline 2015 & 1 \\
\hline
\end{tabular}

En la actualidad ${ }^{10}$ el Colegio de Abogados tiene un número de 194 abogados ejercientes residentes, de los que 59 cursaron sus estudios en la $\mathrm{UNED}^{11}$, lo que implica que prácticamente un tercio del Colegio proceda de la UNED-Melilla.

\section{La actividad formativa}

La presencia de la carrera de Derecho supuso un desarrollo de actividades formativas en el ámbito jurídico, como nunca se había vivido en la ciudad.

Ya en la década de los años ochenta se celebraron las "Jornadas sobre temas Médico-Jurídicos" que tuvieron lugar los días 23 a 27 de marzo de 1987 [1], y fueron clausuradas por el Presidente la Audiencia Provincial de Málaga Manuel Rodríguez López [2]. También los días 29 de febrero a 4 de marzo de 1988 se celebraron las "Las Jornadas Jurídico-Penales” [3], que contaron con destacados ponentes como el mismo Presidente de la Audiencia Provincial de Málaga, Andrés Márquez, ex Director General de Institu-

\footnotetext{
${ }^{10}$ Mayo de 2016.

${ }^{11}$ No se incluyen algunos colegiados que realizaron cursos de la carrera en la UNED Melilla pero finalizaron los estudios y se licenciaron en otras universidades.
} 
ciones Penitenciarias, el Catedrático de Medicina Legal de la Universidad de Granada Enrique Villanueva y el Catedrático de Derecho Penal de la Universidad de Sevilla José María Navarrete [4]. Clausuró estas Jornadas el día 4 de marzo el Presidente de la Sala de lo Penal delTribunal Supremo Enrique Ruiz Vadillo $^{12}$, uno de los juristas del país más brillantes y relevantes del último tercio del s. XX. Este destacado Magistrado había vivido en su niñez en Melilla. Por primera vez volvía a la ciudad e impartía una lección magistral, lo que luego hizo en distintas ocasiones participando en actividades organizadas en la UNED, con la colaboración del Colegio de Abogados. Las Jornadas anuales de Derecho, de las que este año se celebrará la XXIII edición, tomaron a propuesta del Colegio de Abogados, el nombre de Enrique RuizVadillo.

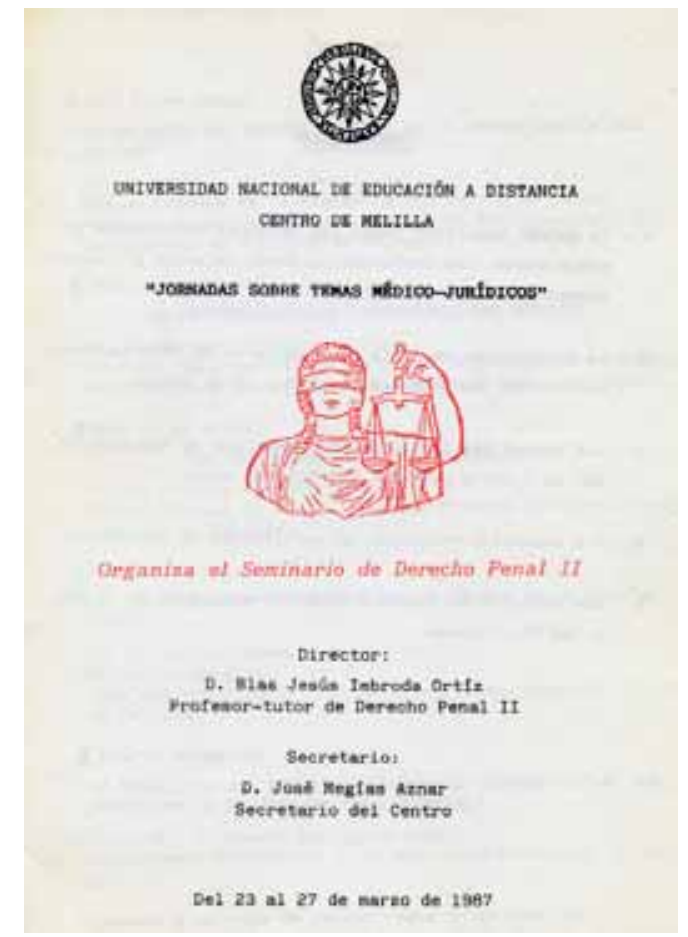

Fig. 1. Jornadas sobre temas médico-jurídicos (marzo 1987). Dibujo del pintor Eduardo Morillas.

${ }^{12}$ Nació el 15 de julio de 1926. Ingresó en la carrera Fiscal y en el cuerpo de Abogados del Estado. Doctor en Derecho. Miembro de la Comisión General de Codificación. Autor de numerosos libros y artículos jurídicos. El 8 de febrero de 1995 fue nombrado Magistrado del Tribunal Constitucional, cargo que ejerció hasta la fecha de su fallecimiento ocurrido el 16 de mayo de 1998. 


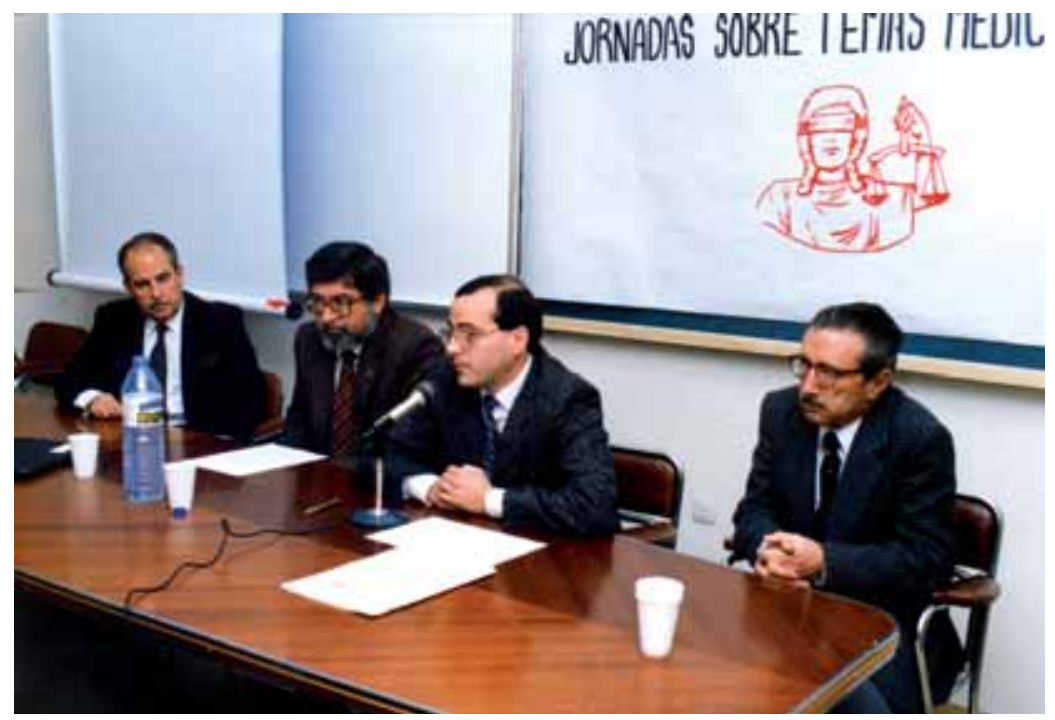

Fig. 2. Jornadas sobre temas médico-jurídicos. Marzo de 1987.

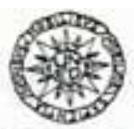

UNTVERSIDAD NACIONAL DE EDUCACION A DISTANCIA CENTRO DE MEIILA

\section{JORNADAS JURIDICO-PENALES}

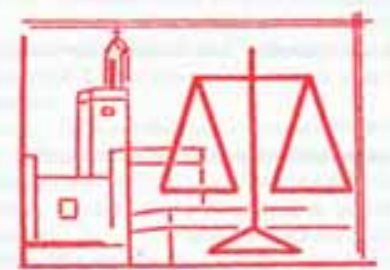

\section{Organiza el Semiaario de Derecho Penal Coordinador Blas Jesiás Imbroda Ortte Profesot-tusor de Derecho Penal II Secretario Jose Megias Aznar Secretario del Centro}

Del 29 de febrero al 4 de marzo de 1988

Fig. 3. Jornadas Jurídico-Penales (marzo 1988). Dibujo del pintor Eduardo Morillas. 


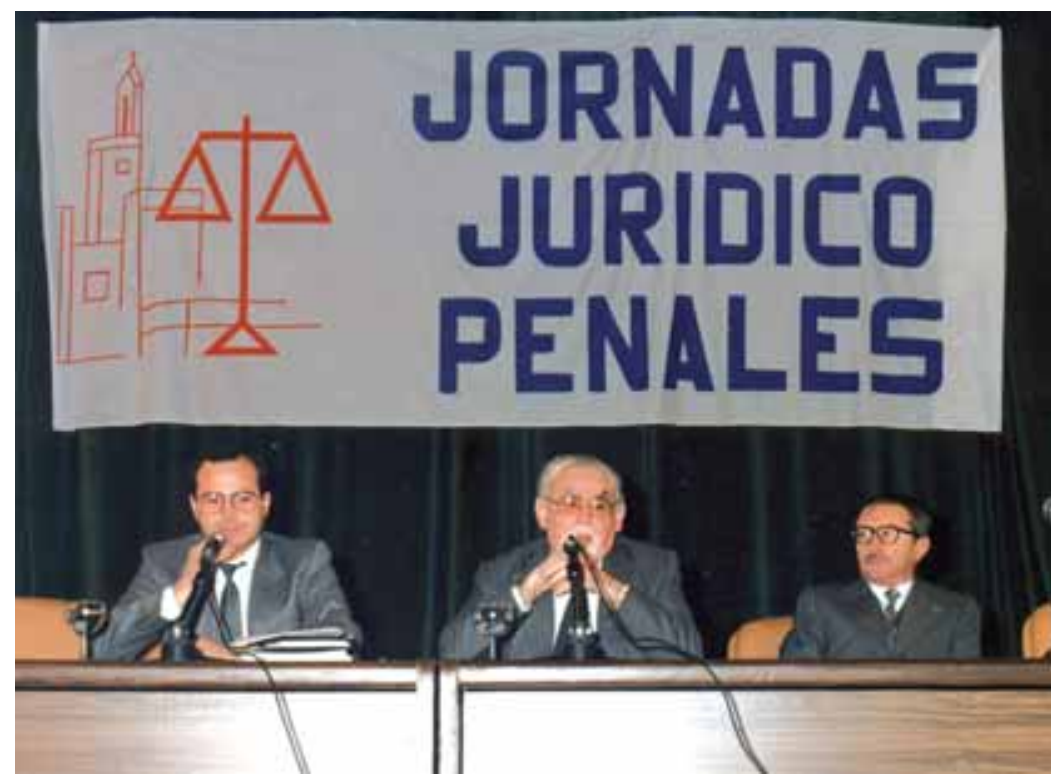

Fig. 4. José María Navarrete, Catedrático de Derecho Penal, junto a Blas Jesús Imbroda y José María Treviño, Magistrado del Juzgado de Primera Instancia de Melilla el 3 de marzo de 1988.

A instancia también del Colegio de Abogados, el día 17 de octubre de 2007, entre los actos que se organizaron en conmemoración del 75 aniversario del Colegio, se le dio el nombre de Enrique RuizVadillo a una de las calles de la ciudad.

Con tres de las conferencias de las Jornadas Jurídico-Penales ${ }^{13}$, y un artículo jurídico más sobre "El delito de impago de prestaciones por separación, divorcio o nulidad de matrimonio" ${ }^{14}$, fue publicada en el año 1992 el número 18 de la revista "Aldaba" del centro de la UNED de Melilla, dedicada al "Monográfico sobre temas jurídico penales" [5]. En la introducción ${ }^{15}$ se decía que: "Podría afirmar que el centro de la Universidad Nacional de Educación a Distancia en Melilla, donde cada día es mayor el número de alumnos en Derecho, ha sido especialmente sensible en el campo de Derecho Penal.Así tuvimos

${ }^{13}$ La conferencia de Manuel Rodríguez López, la de José María Navarrete Urieta y la de Enrique Ruiz Vadillo.

${ }^{14}$ Redactado por Blas Jesús Imbroda Ortiz, págs. 65 a 74.

${ }^{15}$ Redactada por Blas Jesús Imbroda Ortiz, págs. 7 y 8. 
en nuestras aulas al prestigioso Catedrático D. José Antonio Saiz Cantero, melillense que ejercía su docencia en la Universidad de Granada, y que los avatares del destino, nos lo retiró en el esplendor de su carrera, si bien dejando en cuantos fuimos sus alumnos el eterno recuerdo a la brillantez, seriedad, profundidad y honestidad en la docencia. Contamos con ilustres conferenciantes en Jornadas, Seminarios etc., tales como D. Lorenzo Morillas Catedrático y actual Director del Departamento de Derecho Penal de la Universidad de Granada. D. José María Navarrete, Catedrático de Derecho Penal, quien intervino en distintas Jornadas Jurídicas de nuestro Centro. D. Manuel Rodríguez López, Presidente de la Audiencia Provincial de Málaga. D. Andrés García Márquez ex Director General de Instituciones Penitenciarias. D. Enrique RuizVadillo, presidente de la Sala de lo Penal del Tribunal Supremo, recordaba tan gratamente su estancia entre nosotros y su intervención en la Universidad, al igual que cuantos conferenciantes se han desplazado a esta ciudad [6].

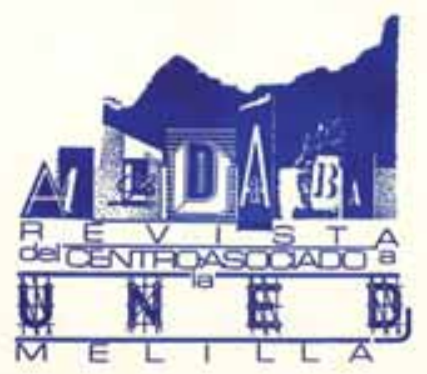

MONOGRAFICO

SOBRE

TEMAS

" JURIDICO-PENALES "

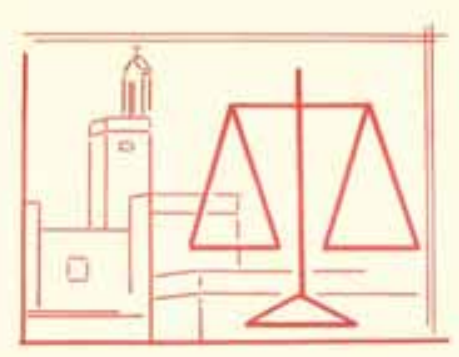

Fig. 5. Portada de la revista Aldaba nº 18, 1992. 


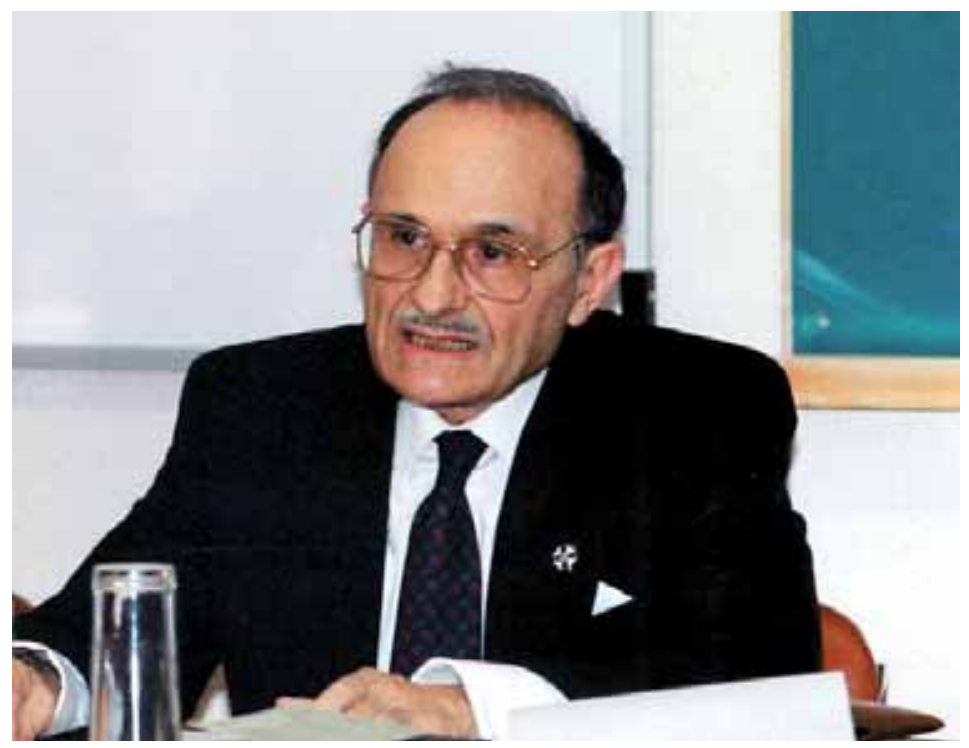

Fig. 6. Enrique Ruiz Vadillo, Presidente de la Sala de lo Penal del Tribunal Supremo, en las I Jornadas de Derecho Procesal, UNED Melilla, 1994.

Junto a ellos, prestigiosos abogados, médicos forenses, fiscales, profesionales de los cuerpos de Seguridad, profesores de Universidad etc., han contribuido en nuestras Aulas mantener una línea de estudio en el campo del Derecho Penal, en unos momentos que requieren en la Universidad especial sensibilidad y atención, ante la continua evolución y transformación, social-política y económica, y su directo y esencial reflejo en el Ordenamiento Jurídico.

Han sido muchos los alumnos, que pasaron por nuestras aulas, y que su dedicación e interés por el Derecho han estimulado la enseñanza en nuestra Facultad así como las actividades complementarias de formación. A ellos deseo, por último, expresar nuestro reconocimiento y agradecimiento».

Entre las primeras actividades jurídicas también debe destacar el primer curso de Prácticas Jurídicas que se organizó y se celebró los días 23 de abril a 29 de junio de $1990^{16}$ [7]. Posteriormente se celebró un curso de actualización legislativa y el seminario de Prácticas Jurídicas ${ }^{17}$.

\footnotetext{
${ }^{16}$ Fue organizador y director el autor de este artículo.

${ }^{17}$ Celebrado el 5 de marzo al 21 de mayo de 1993 fue dirigido por el que fuera Juez Decano de Melilla Enrique Peralta.
} 

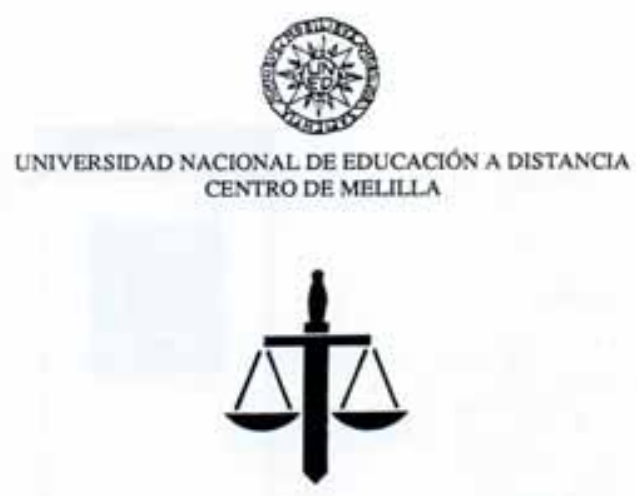

CURSO dE PRÁCTICAS JURÍDICAS

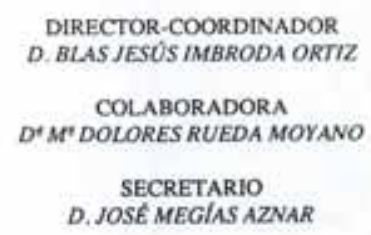

Del 23 de abril al 29 de junio de 1990

Fig. 7. I Curso de Prácticas Jurídicas (abril-junio 1990).

La actividad formativa ha ido creciendo considerablemente. En este ámbito es de destacar la celebración anual de unas Jornadas Jurídicas, que se llevan a cabo desde el año 1994 [8], durante tres días en el mes de junio. Estas Jornadas, a partir de la décima edición ${ }^{18}$ tomó, a petición del Colegio de Abogados, el nombre de Enrique Ruiz Vadillo [9]. Como he indicado anteriormente, estas Jornadas son un referente nacional, no solo por su consolidación (veinticuatro años celebrándose) sino fundamentalmente por el elevado nivel que tienen, que ha generado un alto prestigio en todos los foros jurídicos del país. Por estas Jornadas han pasado los más importantes juristas del país, destacando entre otros a Presidentes del Consejo General del Poder Judicial y del Tribunal Su-

${ }^{18}$ Se celebraron los días 25,26 y 27 de junio de 2003. 
premo, delTribunal Constitucional, Fiscales Generales del Estado, Presidentes de la Audiencia Nacional, Presidentes de todas las Salas del Tribunal Supremo, Catedráticos relevantes en distintas materias, entre otros muchos brillantes juristas que se dan cita anualmente en estas Jornadas.

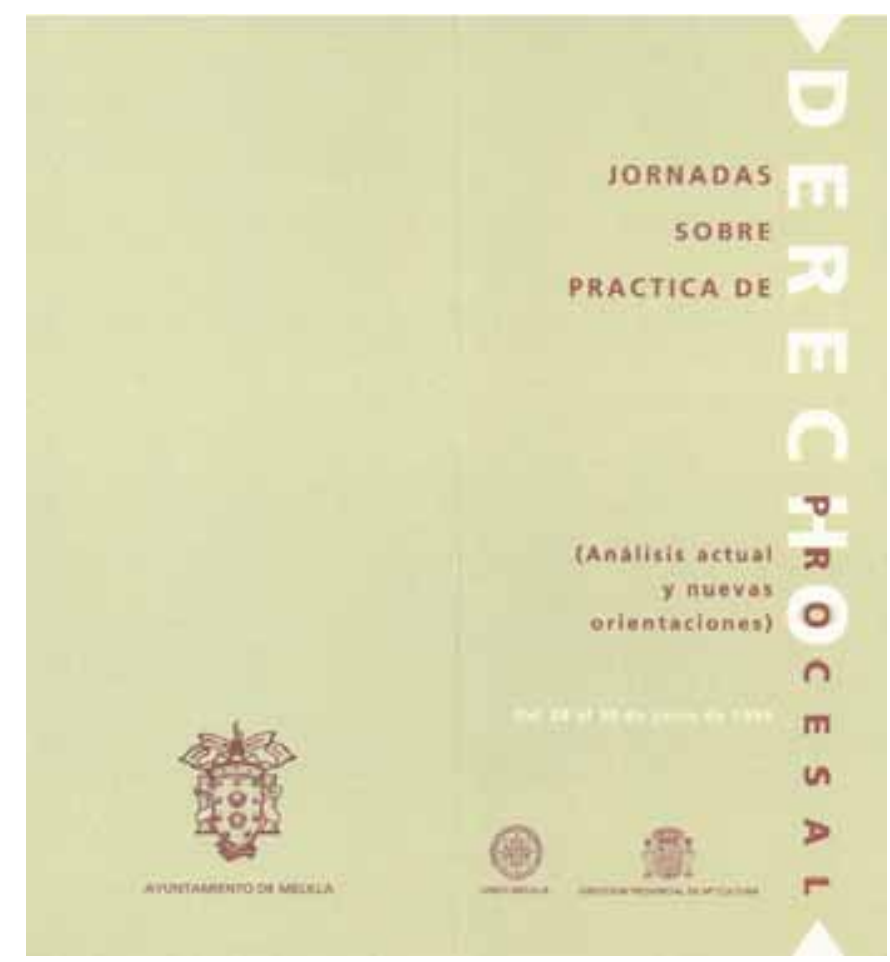

Fig. 8. I Jornadas sobre práctica de Derecho Procesal, UNED Melilla 1994.

Son organizadas por la UNED en colaboración con el Consejo General del Poder Judicial, por lo que se desplazan a la ciudad numerosos Jueces y Magistrados, para asistir al curso. Colabora también en la organización el Colegio de Abogados de Melilla. Es justo reconocer el trabajo que realizan los que desde hace años dirigen estas Jornadas, el Magistrado Manuel Torres Vela [10] y el Catedrático de Derecho Procesal Vicente Gimeno Sendra [11].

Se han seguido realizando numerosas actividades en las que ha participado en su organización el Colegio de Abogados, constituyendo la UNED un lugar de formación, de reflexión y de debate jurídico de máximo nivel [12 y 13]. 


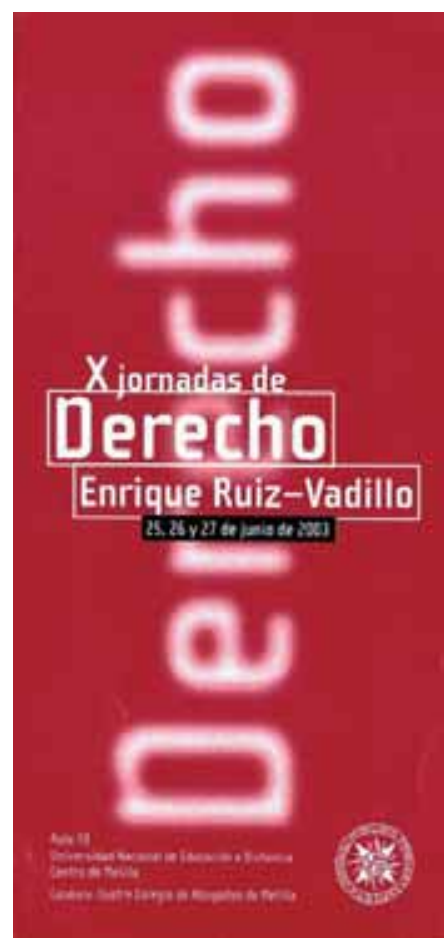

Fig. 9. Jornadas de Derecho Enrique Ruiz Vadillo (2003). A partir de estas X Jornadas tomaron el nombre de Enrique Ruiz Vadillo.

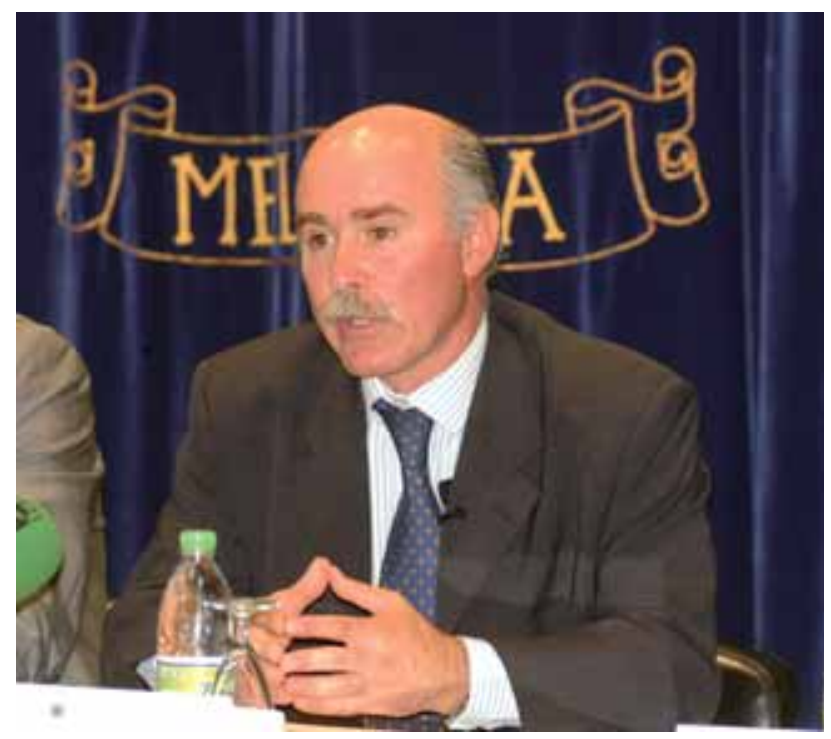

Fig. 10. Manuel Torres Vela, Director Técnico de las "Jornadas de Derecho Enrique Ruiz Vadillo". 


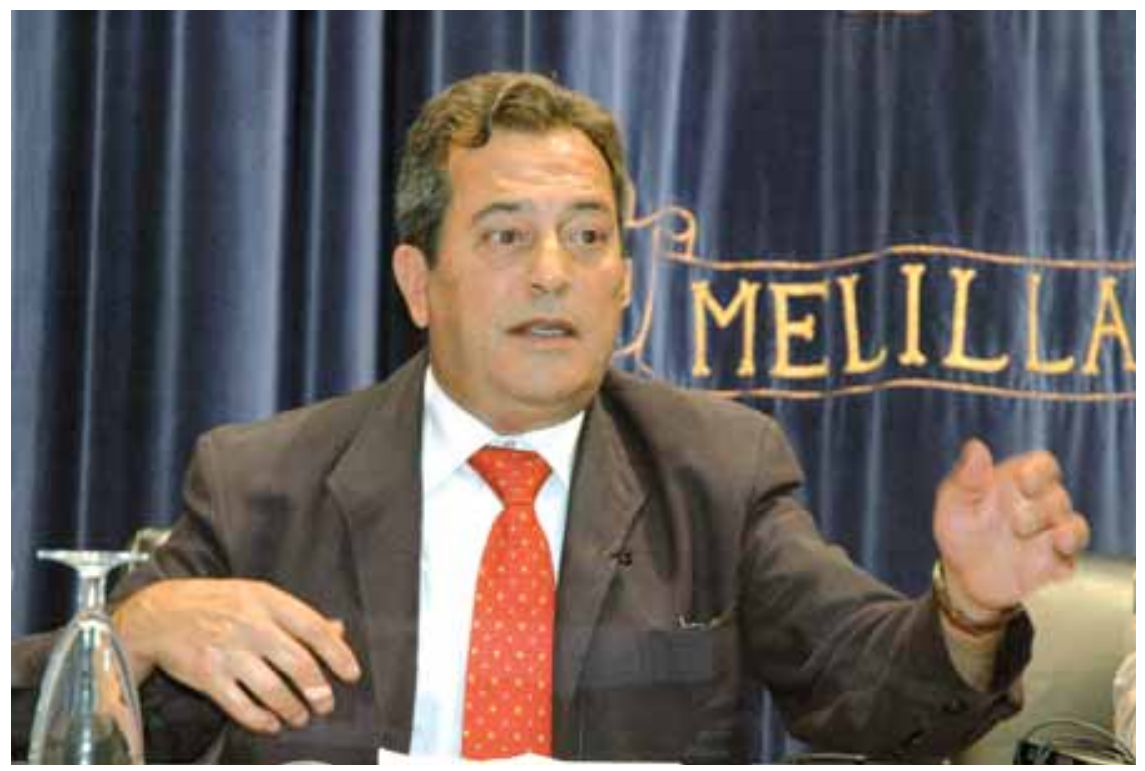

Fig. 11.Vicente Gimeno Sendra, Director Académico de las Jornadas de Derecho Enrique Ruiz Vadillo.

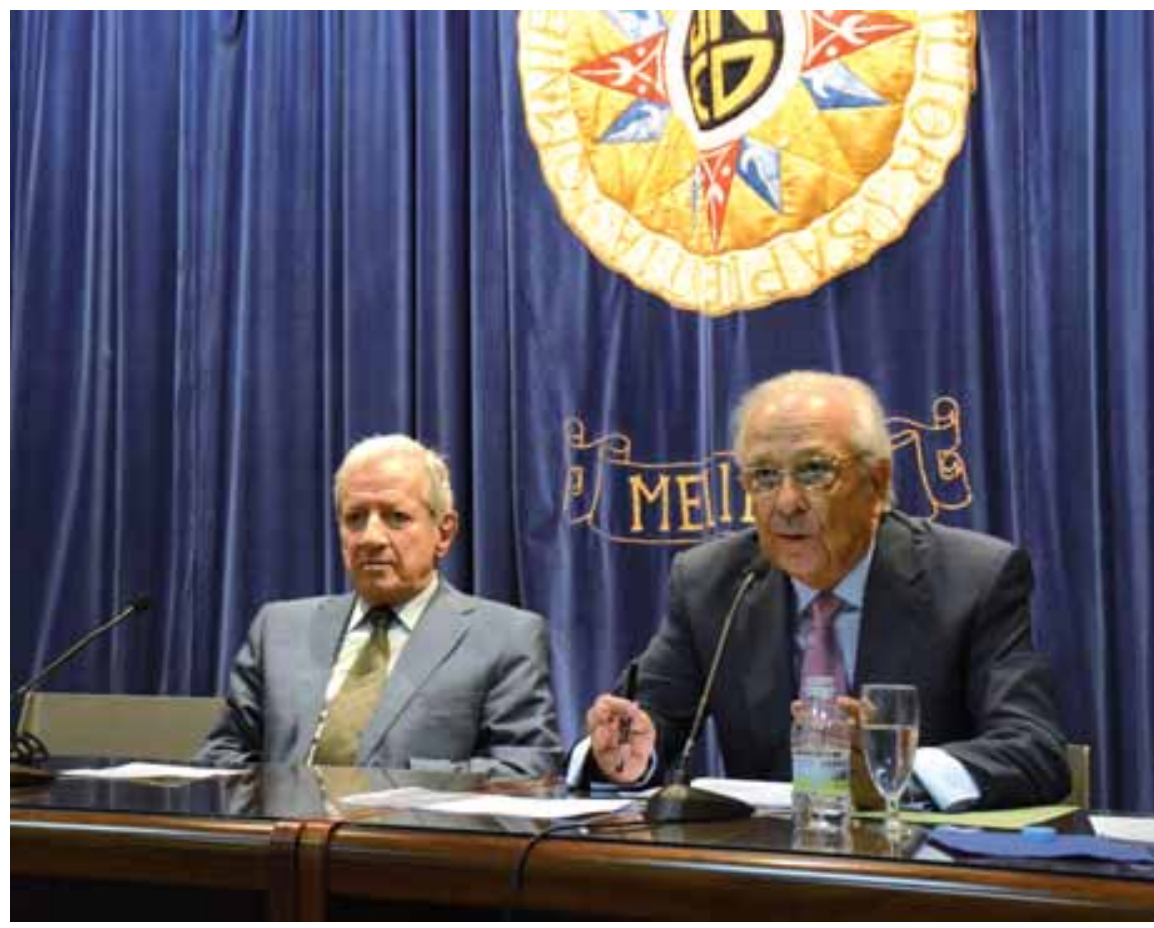

Fig. 12. Pascual Sala Sánchez y Fernando Ledesma Bartret en las Jornadas Jurídicas de Melilla, 2015. 


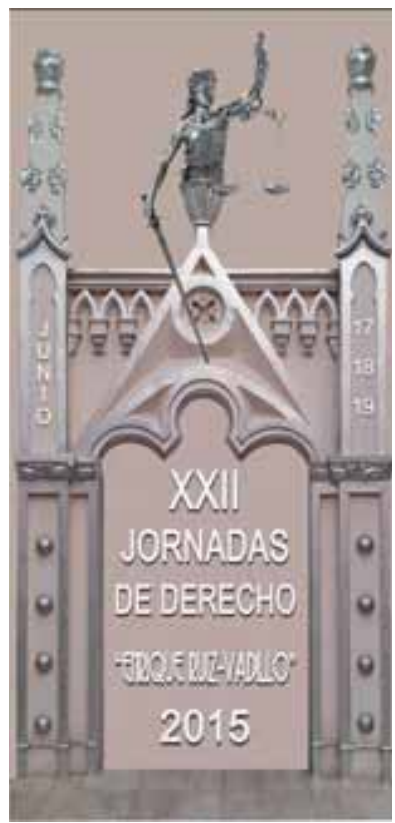

Fig. 13. XXII Jornadas de Derecho “Enrique Ruiz Vadillo”, 2015.

\section{Homenaje a tres Juristas Melillenses}

El Colegio de Abogados de Melilla ${ }^{19}$ en colaboración con la UNED organizó un "Encuentro Jurídico. Homenaje a tres Juristas melillenses", que tuvo lugar los días 21 y 22 de noviembre de 1996 [14]. El primer día se organizaron conferencias con intervención de Catedráticos y Magistrados. El segundo día, viernes, se llevó a cabo un acto solemne en el salón de actos de la UNED en el que el Colegio de Abogados rendía homenaje a tres grandes juristas melillenses, concediéndoles la Medalla de Oro del Colegio. Estos tres juristas eran José Antonio Sainz Cantero ${ }^{20}$ nacido en Melilla en el año 1927, y quien llegó a ser un destacado y brillante Catedrático de Derecho Penal. Falleció repentinamente en el año 1985 cuando ejercía la cátedra en la Facultad de Derecho de la Universidad de Granada. Asistió al acto a recoger la Medalla su viuda, junto a sus hijos y otros familiares.

\footnotetext{
${ }^{19}$ Era Decano en esa fecha Pedro Luis Olivas Cabanillas.

${ }^{20} \mathrm{~A}$ instancias del Colegio de Abogados de Melilla, con motivo del 75 aniversario de su fundación, el 17 de octubre de 2007 se dio el nombre de una de las calles de la ciudad a José Antonio Sainz Cantero.
} 


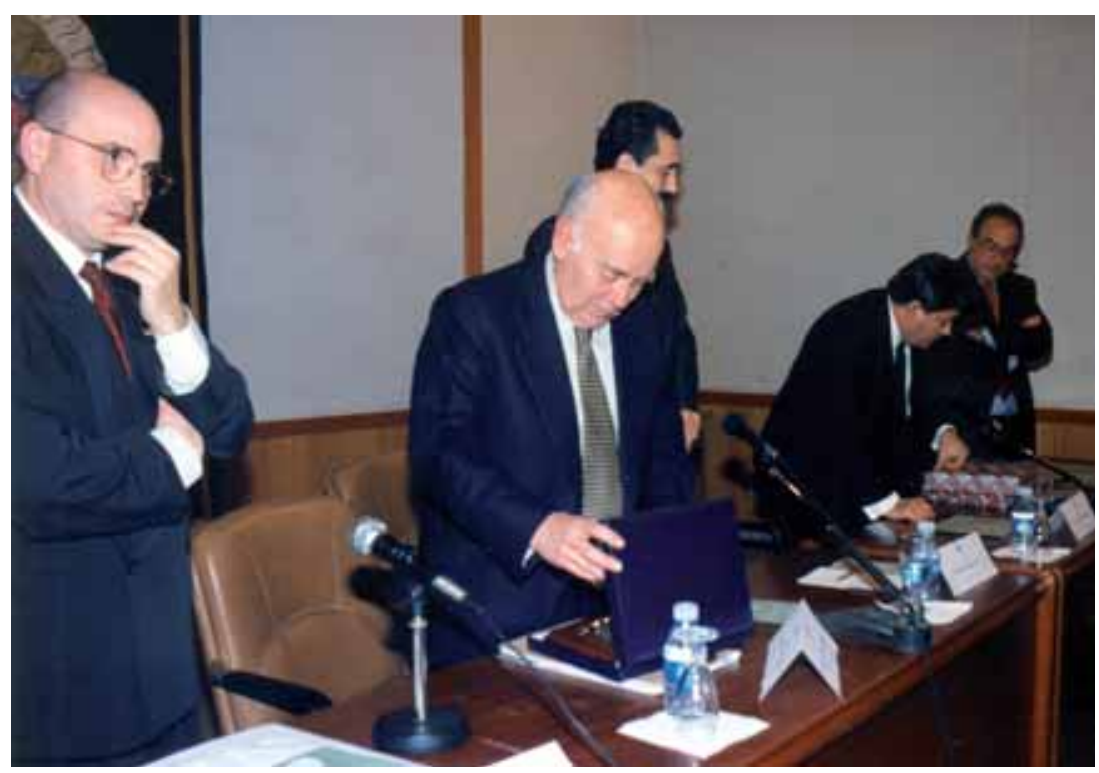

Fig. 14. Carlos Sainz de Robles, Presidente del Tribunal Supremo junto al Diputado de la Junta de Gobierno Blas Jesús Imbroda Ortiz, en el acto homenaje a Juristas Melillenses el 22 de noviembre de 1996.

También se rindió homenaje y se le entregó la Medalla de Oro a Carlos Granados Pérez quien había nacido en Melilla en el año 1944 [15]. Desde el año 1992 era Magistrado de la Sala de lo Penal del Tribunal Supremo. También había sido Fiscal General del Estado. Se homenajeaba a otro destacado jurista con una brillante trayectoria profesional

Por último, se homenajeó también a José Granados Weil [16] quien había nacido en Melilla en el año 1915. Procurador de los Tribunales que desde el 1974 y desde el inicio del Consejo General de Procuradores de España, ostentó la presidencia de dicha institución, ejerciendo la máxima representación de todos los procuradores de los Tribunales de España hasta el año 2001. Se rendía tributo en su ciudad de origen a otro excelente profesional, que ha sido considerado como una de las figuras históricas del mundo jurídico. Falleció en el año 2002.

Melilla a través del Colegio de Abogados y de la UNED ponía en valor a tres juristas nacidos en la ciudad, que habían alcanzado las máximas cotas en sus carreras profesionales del mundo del derecho. 


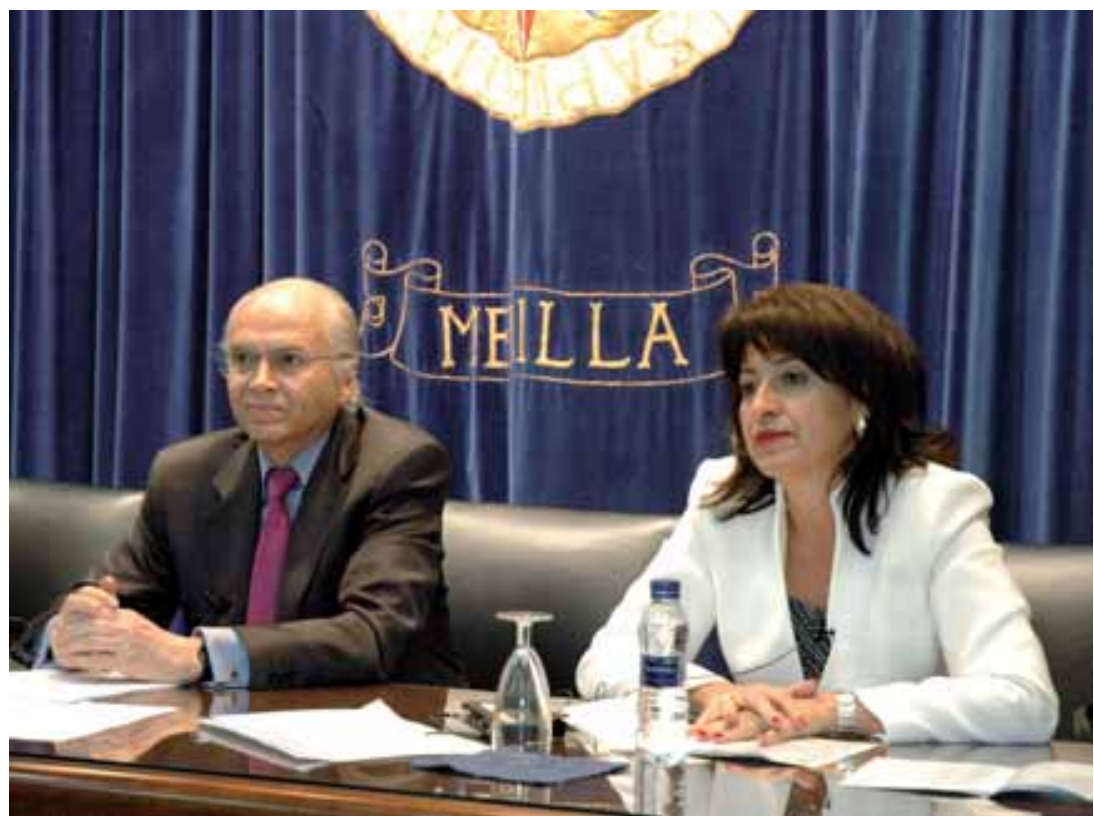

Fig. 15. Carlos Granados Pérez en las Jornadas de Derecho, 2005 junto a la Coordinadora de las Jornadas María Dolores Rueda Moyano.

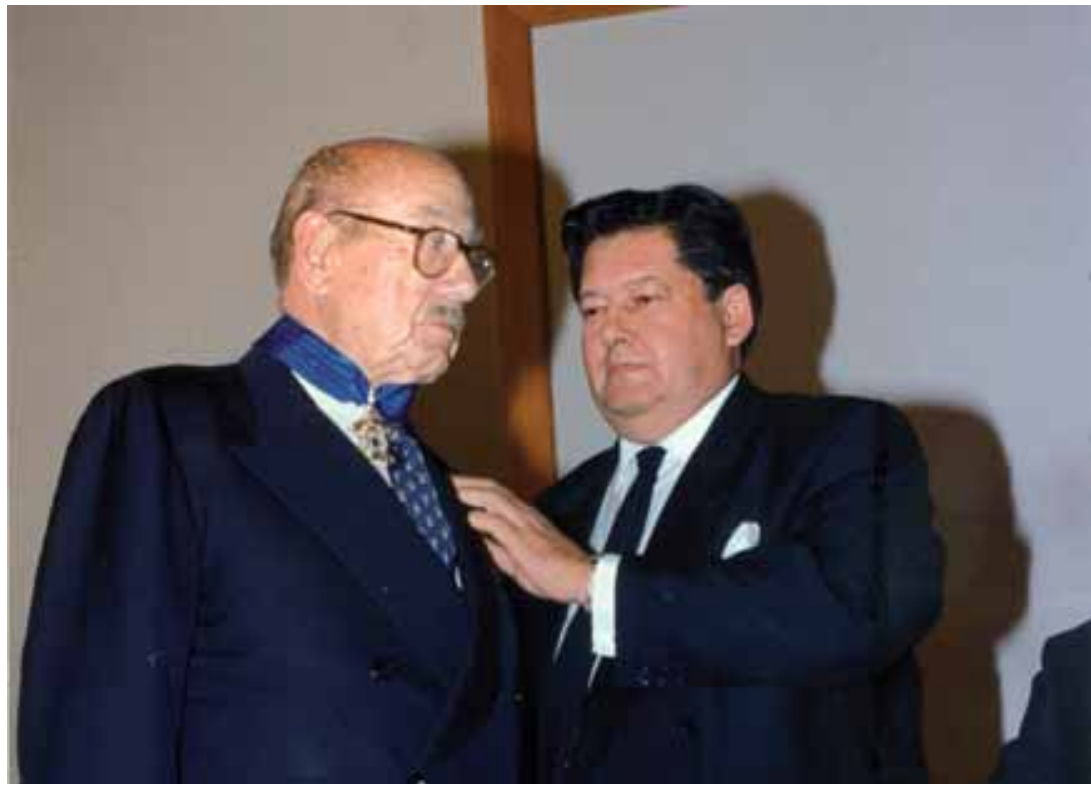

Fig. 16. Entrega de la Medalla de Oro del Colegio de Abogados a José Granados Weil, Presidente del Consejo de los Procuradores de los Tribunales de España por el Decano Pedro Luis Olivas Cabanillas el 22 de noviembre de 1996. 


\section{Concesión de la Medalla de Oro del Colegio de Abogados a la UNED de Melilla}

La Junta de Gobierno del Colegio de Abogados en su sesión celebrada el día 14 de septiembre de 2009 acordó la concesión de la Medalla de Oro al Centro Asociado de la UNED de Melilla. El acuerdo decía: "La Junta de Gobierno reconociendo cuantos innumerables méritos ha contraído el Centro Asociado de la UNED de Melilla para con este colegio, entre los que destacan, además de la estrecha vinculación entre ambas instituciones, la incesante tarea en la formación de Licenciados en Derecho, muchos de los cuales se incorporan a este Ilustre Colegio, su colaboración constante en las actividades formativas de la abogacía melillense, convirtiéndose en un motor de formación continua habitual, y poniendo cuantas veces se ha precisado, los bienes, medios humanos y materiales a disposición de este Ilustre Colegio.

El Centro Asociado de la UNED Melilla siempre ha sido receptivo a las peticiones de colaboración que se le han formulado desde este Colegio de Abogados, para en definitiva formarnos mejor y hacernos mejores abogados.

No puede obviarse también la relevancia y referencia que en la cultura en la ciudad tiene la UNED Melilla, básica también en la complementación de la formación del jurista y del ciudadano.

En Melilla el Centro Asociado de la UNED es el pilar esencial en la formación y en la cultura, por lo que se hace preciso un reconocimiento de la abogacía melillense a esta institución tan arraigada en la sociedad melillense.

Por todo ello la Junta de Gobierno acuerda por unanimidad conceder la medalla de oro del Ilustre Colegio de Abogados de Melilla al Centro Asociado de la UNED de Melilla, por la permanente colaboración con el Colegio de Abogados en la formación continua de la abogacía melillense, por ser constante impulsora del desarrollo cultural e intelectual de la ciudad y por ser centro de origen de la mayor parte de los abogados de Melilla que se han formado en sus aulas".

En el acto solemne de la celebración de la Patrona SantaTeresa de Jesús del año 2009, que tuvo lugar el día 16 de octubre en el Salón del Hospital del Rey, se entregó la Medalla de Oro a la UNED-Melilla, recibiéndola su Director Ramón Gavilán Aragón, alma y pilar de la UNED en Melilla durante su historia [17]. 


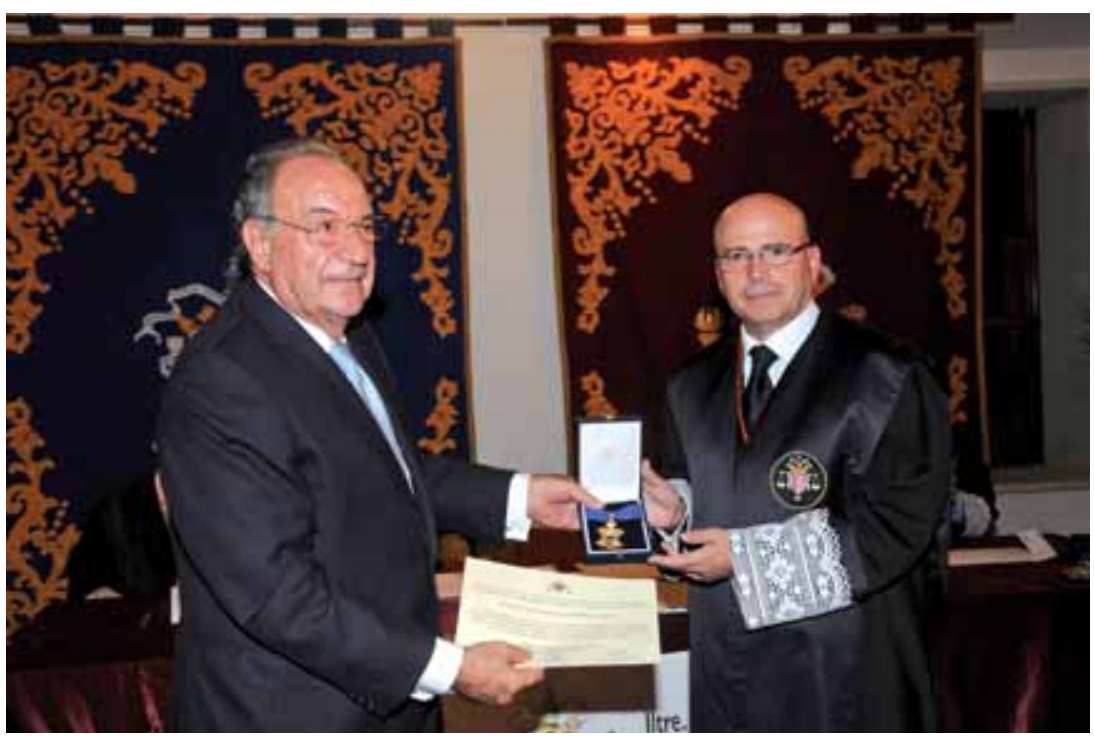

Fig. 17. Entrega de la Medalla de Oro del Colegio de Abogados de Melilla a la UNED Melilla por el Decano del Colegio Blas Jesús Imbroda Ortiz, recibida por el Director de la UNED Ramón Gavilán el 16 de octubre de 2009.

El Colegio de Abogados ha realizado numerosas actividades en colaboración con la UNED, además de contar con su aula y salón de conferencias siempre que precisó de las mismas. Entre muchas actividades podríamos destacar la celebración en el salón de actos de la UNED del acto solemne de la Patrona con la presencia de las Juntas de Gobierno de los Colegios de Abogados de Melilla y Sabadell y la firma del hermanamiento entre los dos Colegios el 17 de octubre de 2008 [18].

La UNED Melilla en la que también la mayor parte de los profesores de la carrera de Derecho ostentan la condición de miembros del Colegio de Abogados, ha sido como se ha dicho anteriormente un continuo motor de actividades culturales y formativas, en todos los órdenes y por supuesto en el jurídico, significando la implantación de la carrera de Derecho en la ciudad por la UNED que el ámbito jurídico haya cobrado una especial significación en la ciudad, además de potenciar notablemente el desarrollo de la profesión de la abogacía [19]. 


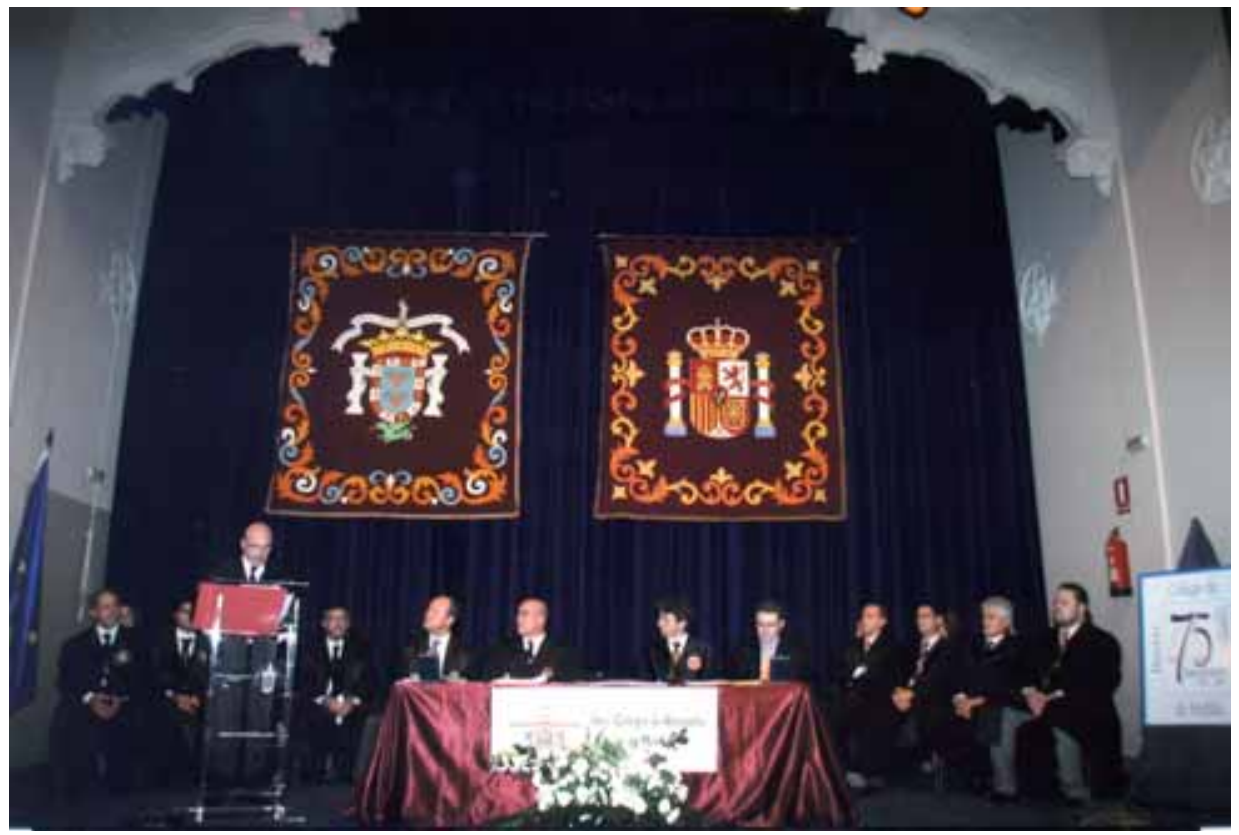

Fig. 18. Acto de la Patrona del Colegio de Abogados de Melilla el 17 de octubre de 2008.

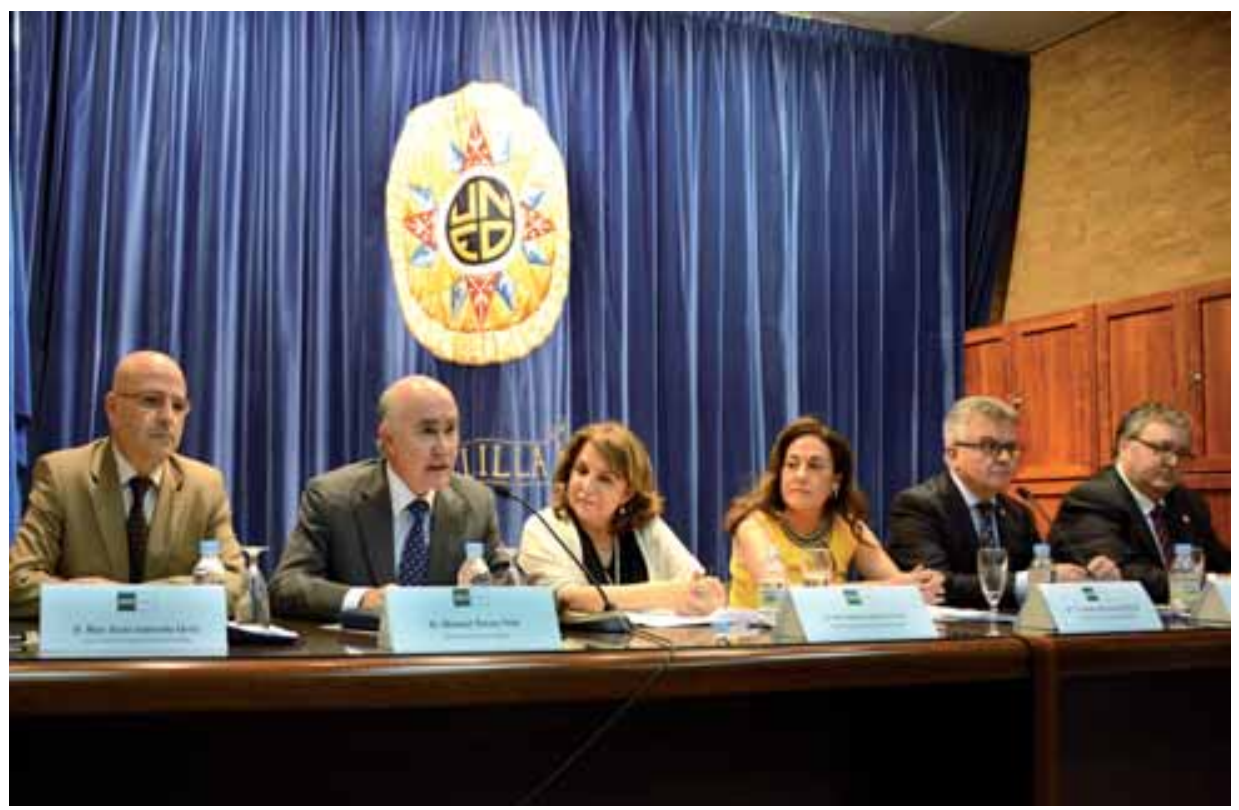

Fig. 19. Inauguración de las XXII Jornadas de Derecho, 2015. 